\title{
Fossils that Change Everything We Know About Human Evolution (...Or Not)
}

\author{
W. Eric Meikle • Andrew J. Petto
}

Published online: 19 August 2010

(C) Springer Science+Business Media, LLC 2010

\begin{abstract}
Dramatic headlines touting new fossil discoveries often proclaim that our view of human evolution has been revolutionized. While this is occasionally the case, it is more often true that new fossils enrich our understanding of our own ancestry or answer scientific questions that could not be resolved with previous data. Even spectacular new discoveries, such as the now famous "hobbit" skeleton (Homo floresiensis), can usually be included in the human family tree without any significant change in the inferences about the phylogenetic relationships or taxonomic status of the rest of its members. It is a testament to the power of evolutionary theory and the careful comparative study of human and other fossils that what we know about human evolution changes so little, even when spectacular new discoveries are announced.
\end{abstract}

Keywords Human evolution P Paleoanthropology ·

Human origins · Teaching human evolution

"Fossil upends theories about evolution of human ancestors"

"Fossil finds challenge view of man's place in evolution"

"African fossils hailed as the 'Rosetta Stone of humanity"”

W. E. Meikle

National Center for Science Education,

PO Box 9477,

Berkeley, CA 94709-0477, USA

A. J. Petto $(\square)$

University of Wisconsin,

Milwaukee, WI, USA

e-mail: ajpetto@uwm.edu
"Scientists announce the discovery of a 47-millionyear-old primate fossil that is set to revolutionize our understanding of human evolution"

This sampling of recent headlines gives the impression that the study of human evolution is so uncertain that the discovery of new fossils throws the whole field into chaos. Because we are all curious about our own origins, whether personal or collective, the subject of human evolution probably attracts more popular attention than any other area of science. New fossil discoveries related in some fashion to human evolution receive more media coverage and are more subject to hype than seemingly any other evolutionary topic. This situation arises from widespread public, and therefore media, interest, along with a normal degree of academic and institutional self-promotion. It's good for these discoveries to receive the attention, but the hype is unhelpful.

In particular, such headlines reinforce one of the most common misunderstandings of human evolution: that almost every significant new fossil leads to at least an important revision-if not a total revolution-in everything previously known in the field. (Part of the reason may be the common misconception that paleoanthropologists are in search of "the missing link"- a transitional form that would clinch, for once and for all, the case for our shared common ancestry with the rest of the primates and without which the case is incomplete. For a discussion of this misconception, see Mead 2009.) In fact, however, the human evolutionary record is now well enough understood in broad outline that most new discoveries fit comfortably into its general framework. New discoveries may provide interesting new data and extend knowledge a bit, but at this point they are very seldom revolutionary. 


\section{The Human Fossil Record}

The history of the discovery of the human fossil record begins in the early nineteenth century. New finds were initially very scattered and sporadic, mostly accidental additions that were poorly dated in absolute terms and usually with little or no context (Lewin 1997). Early in the history of human paleontology, it was difficult to know what to make of these specimens. After all, extinction and the idea that modern humans had biological ancestors of a decidedly different anatomy were still very new concepts. Besides, many of the finds in various sites in Europe were remains of anatomically modern Homo sapiens, which differed very little from the people who discovered them (Lewin 1997).

The situation began to change in 1856, with the discovery of the partial skeleton from the Neander Valley. The Neanderthals were different - different from the previous specimens and different from the people who found them. That they were fossil humans was not widely accepted (even among scientists) until Marcellin Boule's study of the remains from La Chapelle-aux-Saints in France (Boule 1911). There is an excellent review of the history of Neanderthal paleontology in Trinkaus and Shipman (1992).

Deliberate searches for new human fossils and the careful, systematic recovery and analysis of finds were almost unheard of before 1900. Through the first part of the twentieth century, following the development of the professional fields of anthropology and paleontology, more and better fossil finds related to human evolution became a part of the standard science of the day. However, there were still only a few full-time specialists in human evolution, who were investigating only a handful of important fossil sites scattered around the world. Therefore, through the first half of the twentieth century, it was not uncommon for the discovery of new fossils to break entirely new ground, so to speak (for example, Dart 1925; Black 1927; Weidenreich 1937; Broom 1938).

With the growth of academia and of funding for science after World War II, discoveries began to increase more rapidly. Since the middle of the twentieth century, our knowledge of the human fossil record has improved in both quantity and quality to a remarkable degree. New lineages, new species, and more complete and better-preserved specimens, with better collection of contextual data from geology and paleontology, have become standard and expected parts of a field that now has many specialists who are investigating many sites (Lewin 1997).

By the 1980s, human evolution was pretty well understood in broad outline. Continuing discoveries-such as the recently described specimens of Ardipithecus (White et al. 2009) and the "hobbit" Homo floresiensis (Brown et al. 2004) - add great depth and variety of evidence to the big picture of human evolution, but that big picture is little changed from the last quarter of the twentieth century: the first members of the human lineage emerged in Africa, derived from a common ancestor with African apes about seven million years ago and diverged from their ape relatives in the dependence on a new form of locomotion that allowed them to explore new habitats while still retiring to the trees for their safety (for an accessible summary of recent finds, see Sawyer et al. 2007).

\section{The More We Know}

At this point, the record of human evolution is still expanding - both with the discovery of more fossils and with better techniques for study and reconstruction of fossil materials. However, the presentation in popular media of

Table 1 Summary of salient facts about human evolution

\begin{tabular}{lll}
\hline Fact & Known since & Based on \\
\hline $\begin{array}{l}\text { Humans existed in the geological past, long before the } \\
\text { oldest historical records }\end{array}$ & before 1860 & $\begin{array}{c}\text { Archeological sites and artifacts associated with extinct } \\
\text { animal species and ancient geological deposits } \\
\text { Discovery and recognition of Neanderthals } \\
\text { from European sites }\end{array}$ \\
$\begin{array}{l}\text { Fossils of ancient humans exist, some of which are } \\
\text { distinctly different in anatomy from living people }\end{array}$ & 1856 & Discovery of Homo erectus in Java \\
$\begin{array}{l}\text { Some fossil/extinct humans were bipedal, but with } \\
\text { brain sizes two-thirds that of living people }\end{array}$ & 1890s & Discovery of australopithecines in South Africa \\
$\begin{array}{l}\text { Some fossil species had ape-sized brains with large } \\
\text { faces and teeth unlike those of living humans but } \\
\text { were nonetheless bipedal }\end{array}$ & $1920 \mathrm{~s}-1940 \mathrm{~s}$ & Fossil sites in southern and eastern Africa \\
$\begin{array}{l}\text { Multiple lineages of fossil hominids have coexisted } \\
\text { in time and space, some closer to the ancestry of } \\
\text { living people and some wholly extinct } \\
\begin{array}{l}\text { Evidence of frequent stone tool manufacture } \\
\text { appears in the fossil record long after bipedalism } \\
\text { but before major increase in brain size }\end{array}\end{array}$ & $1940 \mathrm{~s}-1950 \mathrm{~s}$ & Fossil sites in eastern Africa \\
\hline
\end{tabular}


new fossil specimens or new analysis of human fossils sometimes obscures just how much and how firmly we know about our fossil relatives and ancestors. Consider, for example, the summary of salient facts about human evolution in Table 1.

These facts about human evolution have been known for many years, and none has been challenged by recent discoveries. These facts are fundamental, and so biology students should learn them and about how they were discovered. But it is also important for students to understand how well established these basic facts of human evolution are. The examples in Table 1 are unlikely ever to be overthrown by new discoveries (with the possible exception of the age of stone tool manufacture, which undoubtedly began before the oldest examples we now know).

Understanding these facts helps in understanding how paleoanthropologists proceed in placing new fossil discoveries in the broad outline of human evolution. For example, suppose that a new fossil human jaw is found. Because jaws and teeth are preserved well in the fossil record, we already know a lot about how these features have changed in the course of history. There is a trend toward smaller teeth, thicker enamel, and shorter jaws that array the teeth in an arch that widens at the back of the jaw (instead of forming parallel rows). So when the new jaw is found, it is possible to see where it fits in the trajectory-more toward the modern condition or more toward the ancestral condition relative to the other specimens that we have studied. The new jaw may represent a previously unknown species, but the broad outline of human evolutionary history has a place for it.

The basic facts of human evolutionary history are solidly established, but this doesn't mean that there aren't a lot of interesting open questions and many significant fossils waiting to be found in coming years. We expect new lineages to be added to the human phylogeny, but very few, if any, of these will "change everything" we know or "overthrow what we thought" about human ancestry. Some interpretations will need to be revised, some nuances will be added, but the main body of well-established evolutionary facts will remain. In the broader picture of what we know about human evolution, most new discoveries are filling in details. If students and the general public recognize this, they will be better prepared to interpret reports of new discoveries and to explore the details of human evolution. It is correspondingly important for teachers to equip their students to recognize this (see the list of Teaching Resources below).

\section{Conclusions}

As more discoveries are reported, our understanding of human evolution grows richer, wider, and deeper. Yet even though we know many more species and have many more partial skeletons than we did even a decade ago, nothing has changed our general understanding of the biological history of humans.

The fundamental understanding of our origins remains:

- We are an African species, derived from ape-like ancestors who pioneered a new sort of locomotion and explored new ecological niches.

- There was a number (at least 22) of variations on that theme: some that came and went relatively quickly and some that persisted for millions of years. We became the sole surviving descendant of our evolutionary family only in the last few tens of thousands of years.

- New biological, behavioral, and cultural characteristics emerged in new lineages, even as ancestral forms continued to occupy traditional ecological niches successfully for many years.

- The success of our lineage appears to have been a commitment to social cohesion and the reliance on improved cognition, perhaps first evidenced in the production of tools and weapons and in the control of fire and later in the emergence of culture and technology.

In a nutshell, we know enough about human evolution to be confident in its broad outlines. Far from revolutionizing the field of paleoanthropology, the discovery of a new species only makes the family tree bushier.

Acknowledgments We are grateful to Eugenie C. Scott for valuable suggestions, to Glenn Branch for advice on and assistance with the manuscript, and to Louise S. Mead for advice on lesson plans and teacher resources.

\section{References}

Black D. On a lower molar hominid tooth from the Chou Kou Tien deposit. Palaeontol Sin. 1927;7(series D 1):1-28.

Boule M. L'homme fossile de la Chapelle-aux-Saints. Ann Paleontologie. 1911;6:106-72.

Broom R. The Pleistocene anthropoid apes of South Africa. Nature. 1938;142:377-9.

Brown P, Sutikna T, Morwood MJ, Soejone RP, Jatmiko, Wayhu Saptomo E, et al. A new small-bodied hominin from the Late Pleistocene of Flores, Indonesia. Nature. 2004;431(7012):1055-61.

Dart RA. Australopithecus africanus: The man-ape of South Africa. Nature. 1925;115:195-9. Available from http://www.nature.com/ nature/ancestor/pdf/115195.pdf. Accessed 20 July 2010.

Lewin R. Bones of contention: controversies in the search for human origins. 2nd ed. Chicago: University of Chicago Press; 1997.

Mead LS. Transforming our thinking about transitional forms. Evo Edu Outreach. 2009;2(2):310-4.

Sawyer GJ, Deak V, Sarmiento E, Milner R, Tattersall I. The last human: a guide to twenty-two species of extinct humans. New Haven: Yale University Press; 2007.

Trinkaus E, Shipman P. The Neanderthals. New York: Knopf; 1992. 
Weidenreich F. The new discovery of three skulls of Sinanthropus pekinensis. Science. 1937;85(2204):316-7.

White TD, Asfaw B, Beyene Y, Haile-Selassie Y, Lovejoy CO, Suwa $\mathrm{G}$, et al. Ardipithecus ramidus and the paleobiology of early hominids. Science. 2009;326(5949):64, 75-86.

\section{Teaching Resources}

From Andrew J. Petto at the University of Wisconsin, Milwaukee. Surprise! A new hominin fossil changes... almost nothing!: a lesson on phylogenetic analysis based on cladograms using hominin fossil data: http://ncse.com/files/pub/evolution/ a_garhi_lesson.pdf

From the Evolution and the Nature of Science Institutes. Human evolution patterns: http://www.indiana.edu/ ensiweb/evol.fs.html

From the David Koch Hall of Human Origins at the Smithsonian Institution. Main Education Resources Page: http://humanorigins. si.edu/education

Mystery Skull Interactive Program: gives students the opportunity to examine anatomical features of hominin skulls and use their observations to identify the hominin taxon: http://humanorigins. si.edu/evidence/human-fossils/mystery-skull-interactive

Lesson plans for teachers: http://humanorigins.si.edu/education/lesson From the Public Broadcasting System. Resources for teachers: http:// www.pbs.org/wgbh/evolution/educators/index.html 